\title{
Intrabiliary argon plasma coagulation hemostasis by direct cholangioscopy for a tricky post-ERCP bleeding
}

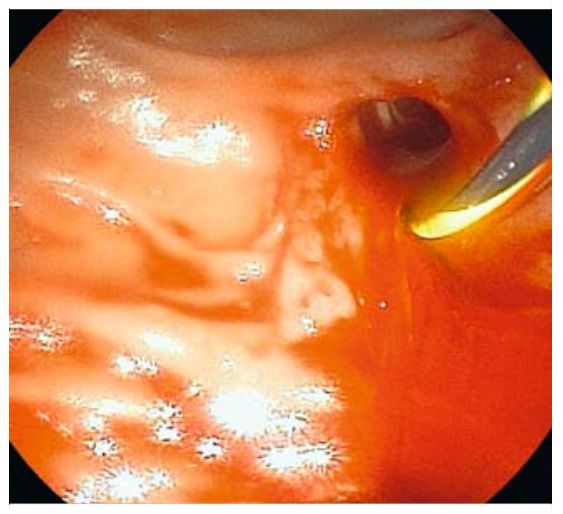

- Fig. 1 Bleeding after endoscopic retrograde cholangiopancreatography was refractory to diluted epinephrine injection (guidewire cannulation).

An 80-year-old man was admitted to the emergency department with fever, jaundice, and abdominal pain due to common bile duct (CBD) lithiasis. His past medical history revealed chronic renal failure and atrial fibrillation, which was treated with warfarin. Therapy with antibiotics and phytomenadione was promptly started, and international normalized ratio values returned to normal.

Cholangiography showed the CBD dilated up to $18 \mathrm{~mm}$ and multiple large stones. Sphincterotomy was performed, followed by papillary pneumatic dilation up to $15 \mathrm{~mm}$ and stone extraction, with no residual filling defect at cholangiography.

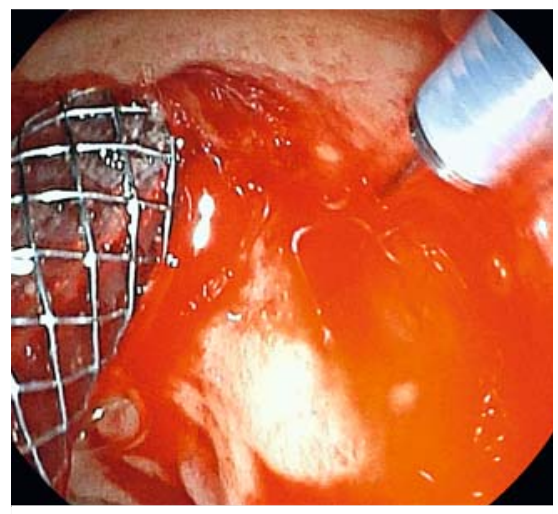

- Fig. 2 Apposed fully covered metallic stent and fibrin glue injection during the first approach.
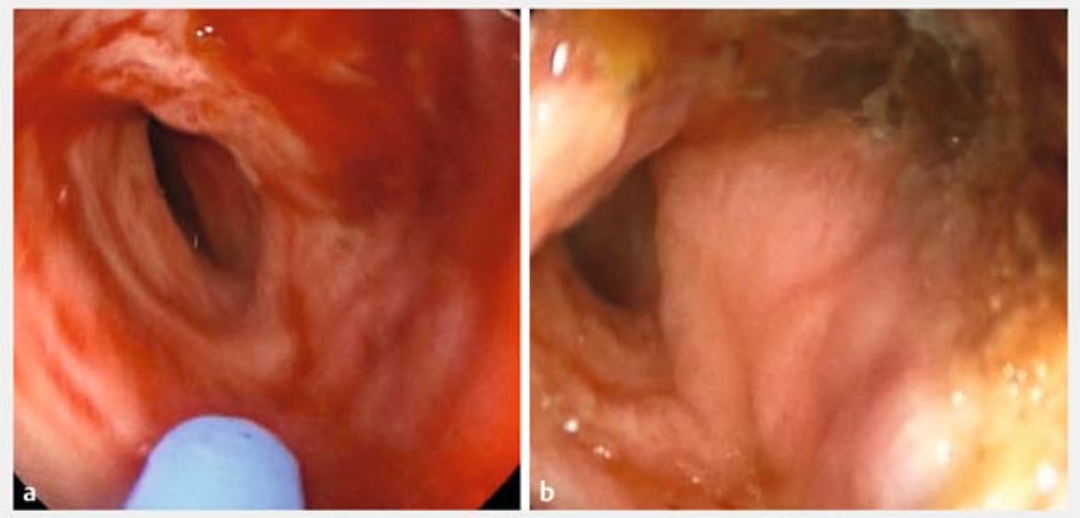

Fig. 4 Direct peroral cholangioscopy. a Argon plasma coagulation of visible oozing vessel. b Hemostasis.

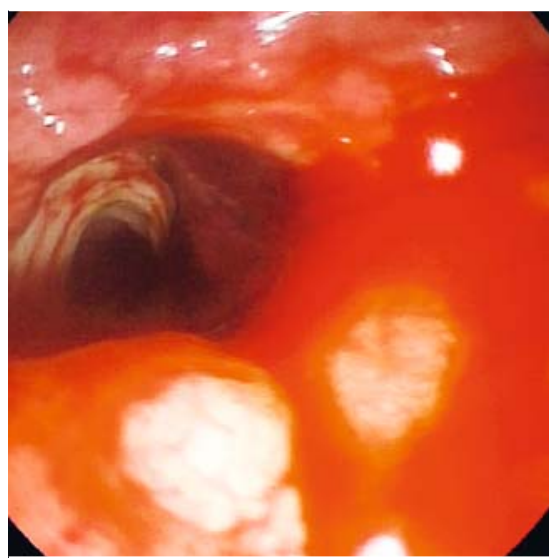

Fig. 3 Common bile duct bleeding source (outside view). 


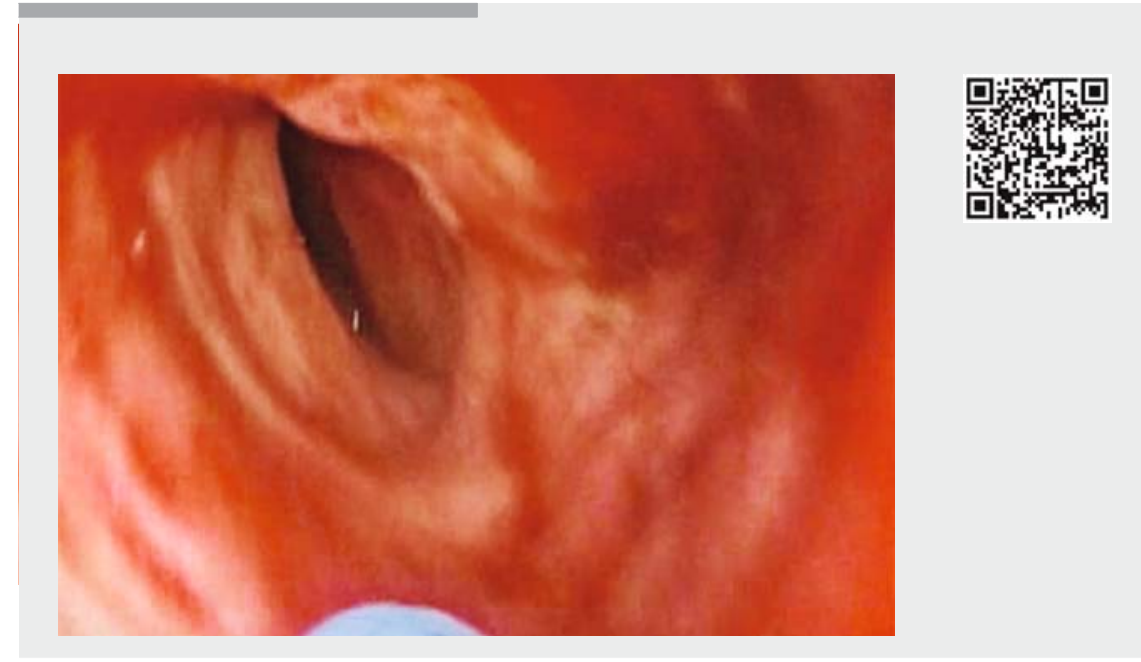

Video 1 Argon plasma coagulation of active bleeding vessel in the distal tract of the common bile duct under direct visualization during cholangioscopy.

The following day, the patient presented signs of hypovolemic shock (hemoglobin $6 \mathrm{~g} / \mathrm{dL}$ ) and melena. Prompt transfusion was organized and an urgent ERCP showed oozing bleeding in the papillary region ( $\triangleright$ Fig.1). Diluted epinephrine was injected, but because of persistent active bleeding, a fully covered metal stent, $40 \times 10 \mathrm{~mm}$, was placed. Fibrin glue (Tissucol; Baxter AG, Vienna, Austria) was injected into the papillary area, resulting in complete hemostasis ( Fig. 2).

After 3 days, another episode of melena and anemia occurred. A further ERCP was performed, and showed a distally migrated biliary stent and visible oozing bleeding coming from the inside the CBD (> Fig. 3).

Direct cholangioscopy was performed using a slim gastroscope (EG530NP, $8.5 \mathrm{~mm}$ thin; Fujinon, Tokyo, Japan), under carbon dioxide insufflation, and showed an active bleeding vessel in the distal tract of the CBD. Argon plasma coagulation was successfully applied (setting Precise 15-20W; Erbe, Tübingen, Germany) under direct visualization ( $\vee$ Fig. 4, \Video 1), with no related adverse events.
The patient's general condition and laboratory tests improved until discharge. There were no clinical signs of bleeding at 6-month follow-up.

This case describes the possible challenges in treating post-ERCP biliary bleeding and a new promising simple approach that should be considered as a part of the endoscopist's armamentarium. To our knowledge this is the first described case of hemostatic APC application in CBD under direct visualization [1-3].

Endoscopy_UCTN_Code_TTT_1AR_2AK

Competing interests

Andrea Anderloni is a consultant for Boston Scientific.

The authors

Andrea Anderloni ${ }^{1}$, Francesco Auriemma ${ }^{1}$, Alessandro Fugazza ${ }^{1}$, Roberta Maselli ${ }^{1}$, Alessandro Repici ${ }^{1,2}$

1 Digestive Endoscopy Unit, Division of Gastroenterology, Humanitas Research Hospital, Rozzano, Milan, Italy

2 Humanitas University, Rozzano, Milan, Italy

Corresponding author

Andrea Anderloni, MD, PhD

Digestive Endoscopy Unit, Division of Gastroenterology, Humanitas Research Hospital, Via Manzoni 56, 20089 Rozzano (Milano), Italy

Fax: +39-02-82242292

andrea.anderloni@humanitas.it 


\section{References}

[1] Chandrasekhara V, Khashab MA et al. ASGE Standards of Practice Committee Adverse events associated with ERCP. Gastrointest Endosc 2017; 85: 32 - 47

[2] Park DY, Park BW, Lee HS et al. Peroral direct cholangioscopic argon plasma coagulation by using an ultraslim upper endoscope for recurrent hepatoma with intraductal nodular tumor growth. Gastrointest Endosc 2007; 66: $201-203$
[3] Vanbiervliet G, Piche T, Caroli-Bosc FX et al. Endoscopic argon plasma trimming of biliary and gastrointestinal metallic stents. Endoscopy 2005; 37: 434-438

\section{Bibliography}

DOI https://doi.org/10.1055/s-0043-124178

Published online: 12.1.2018

Endoscopy 2018; 50: 287-289

(c) Georg Thieme Verlag KG

Stuttgart · New York

ISSN 0013-726X

\section{ENDOSCOPY E-VIDEOS}

https://eref.thieme.de/e-videos

口回 Endoscopy E-Videos is a free Fection, reporting 回舴: on interesting cases and new techniques in gastroenterological endoscopy. All papers include a high quality video and all contributions are freely accessible online.

This section has its own submission website at

https://mc.manuscriptcentral.com/e-videos 